\title{
A recepção serve para pensar: um "lugar" de embates
}

\section{Roseli Figaro ${ }^{1}$ Rafael Grohmann²}

Recibido: 2015-11-30

Enviado a pares: 2016-01-13
Aprobado por pares: 2016-02-09

Aceptado: 2016-02-11

DOI: 10.5294/pacla.2017.20.1.7

Para citar este artículo / to reference this article / para citar este artigo

Figaro, R. y Grohmann, R. (2017). A recepção serve para pensar: um "lugar" de embates.

Palabra Clave, 20(1), 142-161. DOI: 10.5294/pacla.2017.20.1.7

\section{Resumo}

A discussão sobre os estudos de recepção na América Latina coloca-se como uma questão geopolítica, pois nela se imbricam cultura e poder. Nesse sentido, existe um contexto sócio-histórico próprio que deve ser considerado. Os estudos de recepção latino-americanos se posicionam em contraposição às principais correntes que pesquisam a comunicação, as quais apartam os contextos de produção e circulação dos sentidos no cotidiano de embates entre as classes sociais e a cultura popular. A perspectiva teórica hegemônica na comunicação ainda estuda o sujeito como objeto a ser atingido, protegido, alertado ou alienado. Ao retomar essa discussão, procuramos: compreender as relações de forças presentes no processo de produção do conhecimento científico; salientar uma abordagem teórica e metodológica do conceito de sujeito social e de comunicação; discutir como o contexto das últimas duas décadas tem confrontado e desafiado os pesquisadores dos estudos de recepção em sua trajetória de se diferenciarem de abordagens teóricas que retornam com sua concepção linear e de fluxo de comunicação travestidos em "novas" palavras-chave para designar o sujeito da comunicação.

1 Universidade de São Paulo, Brasil. figaro@uol.com.br

2 Universidade de São Paulo, Brasil.rafael-ng@uol.com.br 


\section{Palavras-chave}

Estudos de recepção; comunicação; sujeito; América Latina (Fonte: Tesauro da Unesco).

\section{La recepción sirve para pensar: un "lugar" de enfrentamientos}

\section{Resumen}

La discusión sobre los estudios de recepción en Latinoamérica se posiciona como una cuestión geopolítica, pues ahí se entrelazan cultura y poder. En este sentido, existe un contexto sociohistórico propio que debe ser considerado. Los estudios de recepción latinoamericanos se posicionan en contraposición a las principales corrientes que investigan la comunicación, las cuales apartan los contextos de producción y circulación de los sentidos en el cotidiano de enfrentamientos entre las clases sociales y la cultura popular. La perspectiva teórica hegemónica en la comunicación aun estudia el sujeto como objeto a ser alcanzado, protegido, alertado o alienado. Al retomar esa discusión, procuramos: comprender las relaciones de las fuerzas presentes en el proceso de producción del conocimiento científico; destacar un abordaje teórico y metodológico del concepto de sujeto social y de comunicación; discutir cómo el contexto de las últimas dos décadas ha confrontado y desafiado a los investigadores de los estudios de recepción en su trayectoria de diferenciarse de abordajes teóricos que retornan con su concepción linear y de flujo de comunicación travestidos en "nuevas" palabras clave para designar el sujeto de la comunicación.

\section{Palabras clave}

Estudios de recepción; comunicación; sujeto; Latinoamérica (Fuente: Tesauro de la Unesco). 


\section{Reception is for Thinking: A "Place" for Clashing}

\section{Abstract}

The discussion about reception studies in Latin America is a geopolitical issue, as culture and power intertwine in it. In this sense, there is a socio-historical context that must be considered. Latin-American reception studies are opposed to the main currents researching communication, which separate the contexts of products and circulation from the senses in the everyday clashes between social classes and popular culture. The hegemonic theoretical perspective in communication studies the subject as an object to be reached, protected, alerted or alienated. By resuming this discussion, we seek to: understand the relationships between the forces present in the process of scientific knowledge production; highlight a theoretical and methodological approach to the concept of social subject and of communication; discuss how the context of the last two decades has confronted and challenged the researchers of reception studies in their path to differentiate themselves from theoretical approaches returning with their linear design and of communication flow masquerading as "new" keywords to designate the subject of communication.

\section{Keywords}

Reception studies; communication; individual; Latin America (Source: Unesco Thesaurus). 


\section{Introdução}

Falar em produção teórica no campo da comunicação na América Latina tem várias implicações. Entre elas está, sem dúvida, a de provocar os leitores para as seguintes reflexões: de que modo o espaço geográfico-humano importa para a pesquisa em comunicação? E qual a relação geopolítica, portanto de poder, implicada na adoção da terminologia dos estudos latino-americanos de recepção?

Neste artigo, pretende-se sinalizar caminhos para respostas a essas duas questões, pois esgotá-las seria pretensão demasiada a que não nos propomos, bem como não é o tema central deste trabalho. No entanto, cumprir os objetivos, em seguida elencados, demanda sinalizar nossos pontos de vista a essas indagações.

Dessa forma, contextualizar as duas perguntas anteriores à área de comunicação requer destacar as diferenças e especificidades da América Latina em relação às demais localidades do globo tendo em vista dois eixos: 1) o jogo de forças marcado pela diferença, pluralidade e mestiçagem cultural (Freyre, [1933] 2005; Buarque de Holanda, 2014; Ribeiro, 1970, 1987) e 2) pela especificidade do desenvolvimento capitalista no marco das desigualdades das relações entre "centro" e "periferia" (Prado Jr., [1966] 1987; Pinto, 2008), no jogo da globalização do modelo financeiro-informacional que vem se implantando, desde meados do século XX, como lógica de incorporação subalterna à ordem internacional (Ianni, 1992; Santos, 2000; Furtado, 2003).

Tais eixos podem ser sistematizados como cultura e poder. Esses eixos são mais claramente assumidos por pesquisadores que passam a contestar as orientações teóricas até então únicas em um campo de estudos ainda incipiente e que iniciava sua produção. As teorias hegemônicas orientavam-se, via de regra, pela tradicional influência de concepções deterministas e que traduziam (e traduzem) a comunicação como transmissão linear e direta emissor/canal/receptor e suas implicações no sentido da assimilação, da manipulação ou da resistência. Mais do que isso, a perspectiva teórica hegemônica emanava (e emana) de uma determinada concepção política cujo 
princípio era o da produção científica, que se dava do polo mais forte para a reprodução ao polo mais fraco da cadeia do desenvolvimento capitalista.

Essa afirmação tem como pano de fundo a compreensão de que a ciência faz parte do processo político, econômico e cultural de uma sociedade, não está fora, apartada, nem acima, superior, a esse processo. Essa constatação exige tratar a produção científica na materialidade de seu contexto e acontecimento histórico.

Muniz Sodré (2014) ressalta que o funcionalismo e a mass communication research se atualizaram e continuam pensamentos hegemônicos, o que contribui para a imbricação entre financeirização e comunicação. $\mathrm{O}$ par comunicação-informação, para Sodré (2014, p. 56), "representa um aspecto da luta de classes em que a modernização neoliberal acarreta o desmantelamento do Estado de bem-estar social e da tradicional organização das forças produtivas em favor da precarização do trabalho".

No caso da América Latina e, especificamente, do Brasil, há que se considerar as implicações e os atravessamentos que o jogo de forças de sua posição geopolítica produz sobre o campo da comunicação. O pensamento nacional, que se descortinava nos anos de 1960 em torno de um projeto nacional-popular, estava inspirado na cultura e no protagonismo político de resistência de camadas da população à ordem hegemônica que nos identificava com o projeto norte-americano na Guerra Fria. Assim também era o pensamento latino-americano que ousava nomear-se em alteridade aos hegemônicos discursos da subserviência. Alguns intérpretes do Brasil e da América Latina — de diferentes áreas das humanidades, sobretudo da comunicação-, em sintonia com o movimento social concreto, afirmavam a necessidade de buscarmos alternativas sociais e políticas fortemente embasadas na experiência e na sabedoria das camadas populares (Freire, 1983; Pasquali, [1978] 2007; Beltrán, 1981; Bordenave, 1983; Kaplún, 1985; entre outros).

As ditaduras na América Latina apartaram esse pensamento nacional-popular de suas respectivas populações e criaram, assim, um distancia- 
mento entre eles, o que tornou os discursos sobre a comunicação e a cultura também apartados de toda a experiência vital necessária para o desenvolvimento das pesquisas. É esse distanciamento, inclusive, que propicia, por parte das forças hegemônicas, a consolidação de política de segurança nacional embasada na ampliação e consolidação de um sistema nacional de comunicação no modelo de negócio privado de concessão pública.

Mas, a par do anacronismo das soluções esquemáticas, o movimento político e social pela redemocratização da América Latina e, claro, do Brasil, foi tirando do subterrâneo toda uma camada de experiências com comunicação popular que jogava por terra a dicotomia dos meios de comunicação como "instrumentos de circulação dos símbolos eficazes" (teorias funcionalistas) versus os meios de comunicação feitos para "impedir a atividade mental do espectador" (teoria crítica). Há que se ressaltar o protagonismo das militâncias, que praticaram um outro tipo de comunicação em todo o continente latino-americano (Festa e Silva, 1986; Motta, 1987; Peruzzo, 1998). Os relatos de experiências já são bem conhecidos: as rádios mineiras no Chile, na Bolívia, as rádios livres e comunitárias na Colômbia, no Peru, no Brasil, na Argentina. A imprensa sindical e operária, sobretudo, no Brasil, Chile e na Argentina, os comitês de mães por creches e melhorias nos bairros e os comitês da luta contra a carestia de vida e o desemprego, todos eles discutiam, produziam e circulavam os desafios e os resultados de suas lutas. Eles não existiam para os grandes jornais, nem para a televisão nem para as emissoras de rádio. Protagonizavam uma outra lógica de produção e circulação das informações, da cultura e das reivindicações das camadas populares.

Foi a emergência desses movimentos, que vieram à cena para sustentar a redemocratização política de seus países, que permitiu a reflexão sobre a necessidade de aparatos teórico-metodológicos capazes de conhecer e explicar as relações de comunicação que ali se davam. Dessa forma, como afirma David Morley (2007), é preciso considerar o contexto espacialgeográfico onde ocorre a comunicação.

A emergência dessas experiências comunicacionais populares influencia a universidade e os pesquisadores sensíveis a essas lutas, os quais 
produzem concepções inovadoras sobre as relações de comunicação e o poder das mídias (Ortiz, 1988; García Canclini, 1995; Martín-Barbero, 1997). No Brasil, desenvolve-se daí toda uma linhagem de trabalhos chamados fundadores dos estudos de recepção (Escosteguy e Jacks, 2005; Figaro e Grohmann, 2014).

A partir dessas considerações introdutórias, retomar essa discussão tem por objetivo: 1) demarcar uma compreensão sobre as relações de força sociais e históricas presentes no processo de produção do conhecimento científico; 2) salientar uma abordagem teórica e metodológica do conceito de sujeito social, ser de comunicação; 3 ) discutir como o contexto das últimas duas décadas tem confrontado e desafiado os pesquisadores dos estudos de recepção em sua trajetória de diferenciarem-se de abordagens teóricas que retornam (à moda dos modismos) com sua concepção linear e de fluxo de comunicação — ora o emissor, ora o canal, ora receptor-público-alvo-. Ao cumprir os objetivos antecedentes, espera-se demarcar balizas de abordagens teóricas pertinentes às pesquisas de recepção.

\section{Pertinência e especificidade dos estudos latino-americanos de recepção}

O lugar de produção científica, no caso a América Latina, colabora na conformação das linhas de interesse temático e influencia a capacidade que temos de identificar objetos a serem estudados. Cada cultura tem características que conformam qualquer estudo. Assim, tempo, lugar e os sujeitos históricos compõem a materialidade das linhas de relações que adotam objetos e temas a serem pesquisados e, com isso, demonstra-se o que faz a diferença, o que é importante, o que tem sentido para nós. Não existe uma ciência limpa e despida desses traços. Compô-los e organizá-los é a tarefa do pesquisador.

Desse modo, na América Latina, a cultura popular, fortemente marcada pela oralidade e pela exclusão, fez toda a diferença para os estudiosos da comunicação, ou seja, os dois eixos acima apresentados, cultura e poder, são permeados pelo atravessamento do popular e do subalterno. Esse atravessamento exige dos estudos latino-americanos da comunicação a eleição 
de temas e de problemáticas de pesquisa cujo tratamento teórico-metodológico faz retrabalhar as noções de sujeito/subjetividade e de suas relações com as coletividades às quais pertencem.

Ter em conta essa perspectiva de abordagem desloca e contrapõe-se a teorias deterministas as quais compreendem a comunicação como transmissão linear e direta. A base desse deslocamento dado pelo popular traz como elementos relevantes, no contexto das relações de comunicação, a interação e as intersubjetividades. O conceito de sujeito é o que precisa ser problematizado. O indivíduo/social, sujeito, ao ser contextualizado na complexidade das relações sociais com a coletividade, no cotidiano, nas instituições, nas relações de poder, nas relações de classe, nos conflitos, nos discursos e nas mídias passa a ser compreendido como ser particular e histórico, paciente-agente da transformação social.

Assim, as teorias funcionalistas, hegemônicas em nossa área de estudos, compreendem o receptor como público-alvo/consumidor/audiência. Para os pesquisadores que têm como parâmetro essas teorias, o receptor é parte de um sistema em funcionamento, ele/ela é uma parte, um órgão do sistema; à parte cabe reproduzir a ordem do todo. As premissas do funcionalismo estão nas orientações dos positivistas Comte, Spencer e Durkheim, cujo aspecto teleológico sobrepõe o todo às partes. A palavra recepção/receptor, nas teorias funcionalistas, recobre um campo semântico, portanto, no qual o sujeito se insere em chave conceitual completamente diferente daquelas antes discutidas - do cotidiano, do popular, da coletividade, da luta de classes - norteadoras dos estudos latino-americanos de recepção.

Para exemplificar o sentido de receptor para a linha de "usos e gratificações", de tradição funcionalista, podemos recorrer à síntese de McQuail (2013):

A abordagem de "usos e gratificações" não é estritamente "comportamental", já que sua ênfase principal está na origem social da gratificação pela mídia e nas funções sociais mais amplas dela, por exemplo, ao facilitar contato e interação sociais ou reduzir tensão e ansiedade. (p. 380) 
A partir desses elementos, pode-se argumentar que o ponto central de diferenciação entre as abordagens teóricas está no fundamento de cada qual para explicar as relações sociais, ou seja, para a sociologia funcionalista, as tensões sociais não se dão entre classes, opressor-oprimido, grupos hegemônicos e subalternos, e sim entre indivíduos e interesses; a função principal das instituições é reduzir o atrito e buscar a estabilidade, e a comunicação é instrumento dessa função.

Nessa acepção funcional, podemos afirmar, ao modo de Cabral (2004), que a ciência é compreendida "como um instrumento de regulação, explica o mundo social em termos de estruturas e funções físicas e biológicas similares àquelas do mundo natural” (p. 13). Com essa orientação, as pesquisas, sobretudo, orientadas pela abordagem dos "usos e gratificações”, contribuíram, segundo Escosteguy e Jacks (2005), para “descrever a audiência e seu comportamento" e têm sido úteis "para os propósitos da mídia e insensível às determinações da estrutura social” (Escosteguy e Jacks, 2005, p. 33).

Se o conceito de sujeito nos estudos latino-americanos de recepção tem abordagem diferente dos estudos funcionalistas, o de cultura mais ainda. A cultura, para os funcionalistas, não é processo histórico; é conjunto descritivo de bens, atributos e papéis. Para esclarecer a relevância da cultura nos estudos latino-americanos de recepção, cabe retomar a discussão sobre a importância e a influência dos estudos culturais britânicos no nosso lado do globo. Reportamo-nos aos autores da tradição do Centro de Estudos Culturais da Escola de Birmingham, Raymond Williams, Edward Thompson, Richard Hoggart e de seu continuador Stuart Hall.

Dessa tradição, destacam-se três conceitos-chave: cultura, classes sociais e hegemonia. Esses conceitos fazem repensar os processos de comunicação buscando entender a recepção não como finalidade, mas como parte de um processo cultural-comunicacional maior, no qual os meios de comunicação são entendidos como meios de produção (Williams, 2011). A noção de cultura amplia-se na perspectiva antropológica, na medida em que a contribuição de Raymond Williams traz para o debate a noção de 
cultura como vida cotidiana, aquela vivida e produzida por todos os homens, cujo valor está na capacidade de traduzir os modos, os sentidos, os valores de como as pessoas vivem em sociedade. Ele dá à cultura um sentido contextual e histórico, marcado pelos embates da luta de classes, daí a importância das culturas populares, com sua produção tão valorizada quanto qualquer outra produção cultural literária ou artística. Thompson, por meio de suas pesquisas com a classe operária inglesa, contribui com a noção de classe como experiência, embate de interesses e modos de vida particulares; a classe se manifesta no percurso histórico da luta entre as classes na mudança social. Nessa compreensão das relações entre cultura, sociedade e história, Richard Hoggart deu sua contribuição, sobretudo como primeiro dirigente do Centro de Estudos de Birmingham, e suas investigações centravam-se nas "práticas de resistência de subculturas e de análise dos meios massivos, identificando seu papel central na direção da sociedade" (Escosteguy, 2010, p. 29). A influência do materialismo histórico dialético é marcante e fonte de polêmicas nesse primeiro momento dos estudos culturais, bem como a influência de Gramsci, principalmente com relação às análises sobre ideologia, hegemonia e classes subalternas.

Stuart Hall, pode-se dizer, da segunda geração de estudos culturais, substituiu Hoggart na direção do Centro e foi o autor que polemizou diretamente com os teóricos do estrutural-funcionalismo ao apresentar sua proposta de codificação e decodificação (Hall, [1980] 2003) dos textos da cultura, tendo em vista três perspectivas: 1) leitura de posição hegemônicadominante; 2) leitura de código negociado e 3) leitura de contraposição ao discurso dominante. Nessa fase de sua produção (1972-1979), Hall está observando como os discursos no contexto de sua enunciação, ou seja, do ponto de vista da recepção, travam o embate com as questões ideológicas e trazem à cena os conceitos de classe social, cultura popular, hegemonia, elites. Mais adiante (1997) em suas pesquisas empíricas com outros investigadores (Paul du Gay, Linda Janes e outros), trabalha uma proposta metodológica que trata do circuito da cultura, no qual produção e consumo fazem parte de um processo composto também por regulação, identidade e representação. Por essa proposta metodológica, os discursos são processados nesse circuito em que adquirem sentido. 
As primeiras reflexões dos estudos culturais chegam aos autores latino-americanos, estudiosos da cultura e da comunicação, no contexto dos anos de 1980, quando o modelo maniqueísta de abordagem da comunicação já estava sendo confrontado pela emergência das lutas populares na redemocratização do Continente.

Claro que a influência dos estudos culturais britânicos será lida e incorporada de formas particulares pelas pesquisas na América Latina, e caracterizará de maneiras diversas a produção científica dos pesquisadores que, ou dão maior relevância à recepção das camadas populares por meio de pesquisas empíricas — com entrevistas e observação, assistindo à televisão juntos, fotografando ambientes dos lares etc.—; ou privilegiam a análise dos textos dos produtos culturais no confronto com as falas de populares buscando a produção de sentidos divergentes ou convergentes; ou, ainda, recortam os setores de classe social, ou de mulheres, jovens, crianças e suas relações cotidianas com os meios de comunicação.

Ainda mais uma vez, é preciso firmar as balizas que diferenciam os estudos latino-americanos de recepção daqueles que identificam as pesquisas de recepção com orientação funcionalista. Para os funcionalistas, o sujeito social é um indivíduo que desempenha papéis e ocupa determinados lugares na sociedade e suas ações cumprem as finalidades do todo social. Luta de classes, hegemonia, classes populares são conceitos inexistentes nesse constructo teórico. Escamotear essas divergências seria, no mínimo, falta de conhecimento sobre o tema.

O crescimento das pesquisas empíricas e a renovação conceitual são fatos relevantes para os quais os estudos latino-americanos de recepção contribuíram com o campo da comunicação nas últimas décadas. Assim, é importante reforçar que, na trajetória da abordagem aqui destacada, a nomenclatura recepção nunca foi considerada como o momento último de um processo de comunicação linear e mecânico —este pertencendo aos paradigmas hegemônicos-. Pelo contrário, recepção é um lugar de onde se compreendem os sujeitos comunicacionais. 
Esse embate com os paradigmas hegemônicos tem feito os estudos latino-americanos de recepção se defrontar e retrabalharem o próprio conceito de recepção. Consumo, audiência, prossumidor, circulação são alguns dos temas que voltam constantemente e merecem nossa atenção.

\section{0 deslocamento e o lugar da recepção}

Se, na década de 1990, o termo recepção era muito utilizado, especialmente quanto às mediações de Martín-Barbero (1997), o cenário se modificou nas primeiras décadas do século XXI. A recepção se tornou démodé. Entretanto, quando Escosteguy (2009) levanta a questão de que a recepção já não alcança, o que a autora salienta é uma perspectiva de cultura e poder relacionada aos Estudos Culturais, enquanto circuito de cultura, em que perpassam os sentidos. "Trata-se de um processo muito mais amplo e complexo que diz respeito aos atores sociais e à configuração dos modos de ser" (Escosteguy, 2009, p. 12). Então, a recepção não alcança, em nossa visão, só se for entendida à luz das teorias hegemônicas (estrutural-funcionalistas) da comunicação.

O nome recepção passa então a ser avaliado como démodé, principalmente a partir das reconfigurações tecnológicas das últimas décadas. $\mathrm{O}$ que estão em jogo são as mudanças na relação dos sujeitos com os meios de comunicação, inclusive na internet. Em geral, pergunta-se: "como denominar um sujeito que, a um só tempo, acessa um portal de notícias, cria uma mensagem em um fórum de discussão, envia um e-mail para um amigo e lê uma mensagem postada em um site de relacionamentos?" (Cogo e Brignol, 2010, p. 12).

Essa pergunta é pertinente como estratégia metodológica, mas está centrada no meio, na tecnologia. Por que não se perguntar: como denominar um sujeito que, a um só tempo, assiste à televisão, fala com os amigos ao telefone, tem às mãos o boletim do sindicato e prepara o jantar da família? O que nos interessa nas pesquisas dos estudos latino-americanos de recepção é compreender como os sujeitos se relacionam com os meios de comunicação, como se dão as relações de comunicação e como se constroem os efeitos de sentidos. 
De fato, nos termos de uma renovação se multiplicam as terminologias, como uma forma de demarcar um terreno teórico. Castells (2009) fala em prossumidor ${ }^{3}$ e produser; Jenkins (2008) ajuda a alavancar os estudos sobre os "fãs", além de ajudar a disseminar (ou espalhar — para ficar em seu próprio conceito de spreadable media - Jenkins, Green e Ford, 2014) termos como convergência, narrativas transmídia e mesmo spreadable media. Enquanto isso, Shirky (2011) comenta acerca da "cultura da participação". Mas o que eles entendem por participação e, consequentemente, por sujeito? Nota-se que Jenkins, Green e Ford (2014) procuram entender "participação" como um paradigma diferente daquele relacionado à "resistência".

\begin{abstract}
Esse foco na "resistência" é compatível com a linguagem empregada pelos escritores nos estudos culturais e críticos que são tradição desde os anos 1980. Atualmente, os acadêmicos são muito mais propensos a falar sobre política com base na "participação", refletindo um mundo onde mais poder da mídia fica nas mãos dos cidadãos e dos membros do público, ainda que a mídia de massa possua uma voz ativa privilegiada no fluxo das informações. A sinta$x$ diz a nós todos algo essencial sobre esses dois modelos. Somos resistentes a algo: ou seja, somos organizados em oposição a um poder dominante. Participamos em algo, ou seja, a participação é organizada em e através das coletividades e conectividades sociais. (Jenkins, Green e Ford, 2014, p. 206)
\end{abstract}

Entendemos que o conceito de participação deve ser tomado em seu sentido democrático — e por isso é necessária a inter-relação com "resistência” —. Se participar significa somente estar "integrado" ao sistema a partir das "interações em rede" hegemônicas, então se esvazia a noção de comunicação a partir das relações de poder. Segundo Fuchs (2014), os autores de Cultura da conexão reduzem participação a uma dimensão cultural e ignoram, assim, a noção de democracia participativa e suas implicações para a internet. Por exemplo, comunidades fascistas na internet não podem ser consideradas como uma amostra da "cultura participativa" e da "cultura de fã”. "Participação significa que os seres humanos têm o direito de fazer parte das decisões, governar e controlar as estruturas que os afetam. Direitos são universais e não particularistas" (Fuchs, 2014, p. 57).

3 Cujo debate conceitual nosso artigo não alcançará neste momento. 
O que podemos perceber, então, é que o conceito de recepção é relegado a segundo plano, assim como o conceito de resistência, ao passar para a "linha de frente teórica" termos como criatividade e participação. Isto é, há uma concepção de sujeito limitada às "diferenças interacionais" e que não concebe relações de poder, desigualdade e hegemonia.

Do mesmo modo que a nomenclatura do sujeito é questionada, o próprio nome também o é. Afinal, do que estamos tratando quando falamos em recepção? Consumo? Circulação? Usos? Scolari (2008) afirma que o termo usos se relaciona a certo "taylorismo digital" que considera somente a métrica dos cliques. "Se Taylor se propunha a reduzir o número de movimentos de um operário para incrementar sua produtividade, o expert em usabilidade quantifica e trata de reduzir o número de cliques" (Scolari, 2008, p. 254-255). Portanto, quando nomeamos algo, é preciso se atentar ao que essa denominação quer dizer.

Em nossa visão, os estudos latino-americanos de recepção podem tratar de consumo cultural, consumo midiático (Toaldo e Jacks, 2013), circulação (Fausto Neto, 2010), consumo midiatizado (Trindade e Perez, 2014) ou quaisquer outras terminologias desde que haja uma concepção de sujeito social-comunicacional envolvida, bem como considere as relações de poder, sem separar os contextos de produção e circulação dos sentidos dos embates que envolvem classes sociais e cultura popular. Trata-se, portanto, de um ponto de vista comum sobre os sujeitos/objetos de estudo. E, como afirma Lopes (2011, p. 414), "as categorias-chave da pesquisa de recepção são mais, e não menos, significantes no ambiente das novas mídias”.

No mesmo contexto, os estudos latino-americanos de recepção trazem à tona a ordem do comunicacional, não do estritamente midiático (Lopes, 2014). São das correntes midiológicas e que consideram o meio como o centro de tudo que os estudos latino-americanos de recepção se afastam. Na verdade, em contexto de spreadable media (Jenkins, Green e Ford, 2014), faz ainda menos sentido centrar os estudos em um meio ou plataforma, pois o que interessa são as produções de sentido em circulação nas relações de comunicação. Porém, é bom salientar que se afastar de uma 
concepção determinista dos meios não significa esquecer os meios e como os "dispositivos comunicacionais" (Maingueneau, 2008) produzem sentido. As "múltiplas telas" evidenciam, na verdade, o que foi chamado de "lado oculto do receptor" (Sousa, 1995) e isso é o que realmente interessa para a compreensão do "circuito da cultura". Aos estudos de recepção importam os sujeitos e os sentidos do que eles consomem, produzem e circulam em suas relações de comunicação. Os receptores não são assujeitados ou efeitos de estruturas ou enunciações. Eles são produtores de sentido e da própria história, embora não detenham controle da totalidade desse processo. Totalidade que deve ser considerada nas pesquisas e análises da recepção; afinal, é o circuito da produção-consumo que chamamos de recepção.

Na jovem tradição latino-americana (se é que assim se pode reivindicar), os estudos de recepção servem para questionar hegemonias, não para reforçá-las ou somente para exaltar a participação e a criatividade dos "usuários". As palavras mágicas do momento, como prossumidor por exemplo, não podem ser naturalizadas. É preciso, dessa forma, resgatar uma abordagem crítica do processo comunicacional, lembrando o que diz Martín-Barbero (1997) de que o olhar da recepção não desconsidera a totalidade do processo comunicacional. Ou como afirma Roger Silverstone (2002):

A circulação de significados, que é a mediação, é mais do que um fluxo em dois estágios - do programa transmitido via líderes de opinião para as pessoas na rua-, como Katz e Lazarsfeld (1955) defenderam em seus estudos [...] Os significados mediados circulam em textos primários e secundários [...], em que nós, como produtores e consumidores, agimos e interagimos procurando compreender 0 mundo [...]. Mas também, e ao mesmo tempo, usamos os significados da mídia para evitar o mundo, para nos distanciar dele, dos desafios talvez impostos pela responsabilidade e pelo cuidado, para fugir do reconhecimento da diferença. (Silverstone, 2002, p. 33-34)

Importa, pois, salientar essa abordagem crítica, de uma ciência que se propugna compreender a comunicação como centro dos embates econômicos e políticos que se dão na contemporaneidade com um olhar a partir de nossa localização geopolítica. 
Do mesmo modo que García Canclini (1995) afirmou "o consumo serve para pensar", podemos parafraseá-lo e dizer que "a recepção serve para pensar": a especificidade do espaço geográfico-humano para os estudos de recepção na América Latina, a necessidade ainda maior de se pensar as questões de cultura e poder em tempos de "hegemonia da convergência" e "financeirização da comunicação" (Sodré, 2014). Serve para pensar a recepção como um lugar de lutas e embates, não de transmissões e apenas consensos. Serve, enfim, para evidenciar que aqui também se produz conhecimento teórico, epistemológico e metodológico da comunicação. Por isso, a par das tergiversações em nosso campo que auspiciam proximidades entre pesquisas funcionalistas e de estudos culturais, de forma modesta, afirmamos: a recepção ainda serve.

\section{Referências}

Beltrán, L. R. (1981). Estado y perspectivas de la investigación en Comunicación Social en América Latina. Em Pontificia Universidad Javeriana, Faculdade de Comunicação Social (Org.), Memorias de la Semana Internacional de la Comunicación. Bogotá.

Bordenave, J. D. (1983). Além dos meios e mensagens. Petrópolis: Vozes.

Buarque de Holanda, S. (2014). Raízes do Brasil. 26a ed. São Paulo: Companhia das Letras.

Cabral, A. (2004). A sociologia funcionalista nos estudos organizacionais: foco em Durkheim. Cadernos Ebape, FGV, II(2), 1-15. Recuperado em 8 fev. 2015 de www.ebape.fgv.br/cadernosebape

Castells, M. (2009). Communication Power. Nova York: Oxford.

Cogo, D. e Brignol, L. D. (2010). Redes Sociais e os Estudos de Recepção na Internet. Em Associação Nacional de Pós-graduação em Comunicação (Org.), Anais do XIX Encontro Anual da Compós. Rio de Janeiro: Pontifícia Universidade Católica do Rio de Janeiro. 
Escosteguy, A. C. (2009). Quando a recepção já não alcança: os sentidos entre a produção e a recepção. E-Compós, 12(1), 1-15.

Escosteguy, A. C. (2010). Cartografias dos estudos culturais. Uma versão latino-americana. Edição on-line. Belo Horizonte: Autêntica. Recuperado em 17 fev. 2016 de https://pt.scribd.com/doc/35295718/ Cartografias-dos-estudos-culturais-Uma-versao-latino-americana

Escosteguy, A. C. e Jacks, N. (2005). Comunicação e recepção. São Paulo: Hacker.

Fausto Neto, A. (2010). As bordas da circulação. Alceu: revista de Comunicação, Cultura e Política, 10(20), 55-69. Recuperado em 17 fev. 2016 de http://revistaalceu.com.puc-rio.br/media/Alceu20_Neto.pdf

Festa, R. e Silva, C. E. (Orgs.) (1986). Comunicação popular e alternativa no Brasil. São Paulo: Paulinas.

Figaro, R. e Grohmann, R. (2014). O Conceito de Classe Social em Estudos de Recepção Brasileiros. Animus: Revista Interamericana de comunicação midiática, 13(25), 57-70. Recuperado em 17 fev. 2016 dehttp://cascavel.ufsm.br/revistas/ojs-2.2.2/index.php/animus/ article/view/15775

Freire, P. (1983). Extensão ou comunicação? 7a ed. Rio de Janeiro: Paz e Terra.

Freyre, G. (2005). Casa grande e senzala. 50ª ed. São Paulo: Global.

Fuchs, C. (2014). Social Media: A critical introduction. Londres: Routledge.

Furtado, C. (2003). Raizes do subdesenvolvimento. Rio de Janeiro: Civilização Brasileira.

Garcia Canclini, N. (1995). Consumidores e cidadãos. Conflitos multiculturais e globalização. Rio de Janeiro: Editora da Universidade Federal do Rio de Janeiro. 
Gay, P. du, Hall, S., Janes, L., Mackay, H., Negus, K. et al. (1997). Doing Cutural Studies. The story of the Sony walkman. Londres: Open University/Sage.

Gramsci, A. (1978). Obras escolhidas. São Paulo: Martins Fontes.

Hall, S. (2003). Da diáspora. Identidades e mediações culturais. Belo Horizonte/ Brasília: Universidade Federal de Minas Gerais/Unesco Brasil.

Hoggart, R. (1973). As utilizações da cultura: aspectos da vida cultural da classe trabalhadora. Lisboa: Editora Presença.

Ianni, O. (1992). Sociedade Global. São Paulo: Civilização Brasileira.

Jenkins, H. (2008). Cultura da convergência. São Paulo: Aleph.

Jenkins, H., Green, J. e Ford, S. (2014). Cultura da conexão: criando valor e significado por meio da mídia propagável. São Paulo: Aleph.

Kaplún, M. (1985). El comunicador popular. Quito: Centro Internacional de Estudios Superiores de Comunicación para América Latina.

Lopes, M. I. V. de (2011). Uma agenda metodológica presente para a pesquisa de recepção na América Latina. Em N. Jacks (Org.), Análisis de recepción en América Latina: un recuento histórico con perspectivas al futuro (pp. 409-428). Quito: Centro Internacional de Estudios Superiores de Comunicación para América Latina.

Lopes, M. I. V. de (2014). Mediação e recepção: algumas conexões teóricas e metodológicas nos estudos latino-americanos de comunicação. Revista MATRIZes, 8(1), 21-44.

Maingueneau, D. (2008). Análise de textos de comunicação. São Paulo: Cortez.

Marques de Melo, J. (1999). Paradigmas da escola latino-americana de comunicação. Revista Latina de Comunicación Social, 19. Recupera- 
do em 8 fev. 2015 de http://www.ull.es/publicaciones/latina/ a1999fil/73melop.htm

Martin-Barbero, J. (1997). Dos meios às mediações. Comunicação, cultura e hegemonia. Rio de Janeiro: Editora da Universidade Federal do Rio de Janeiro.

McQuail, D. (2013). Teorias da comunicação de massa. 6a ed. Porto Alegre: Penso.

Morley, D. (2007). Media, Modernity and Technology: The geography of the new. Londres: Routledge.

Motta, L. G. (1987). Brasil: alternativa popular: comunicação e movimentos sociais. Em M. S. Grimberg, (Org.) A comunicação alternativa na América Latina (pp. 37-71). Petrópolis: Vozes.

Ortiz, R. (1988). A Moderna tradição brasileira: cultura brasileira e indústria cultural. São Paulo: Brasiliense.

Pasquali, A. (2007). Comprender la comunicación. Edição revisada e atualizada. Barcelona: Gedisa.

Peruzzo, C. M. K. (1998). Comunicação nos movimentos populares: a participação na construção da cidadania. Petrópolis: Vozes.

Pinto, Á. V. (2008). A sociologia dos países subdesenvolvidos. Rio de Janeiro: Contraponto.

Prado Jr., C. (1987). A revolução brasileira. $7^{\text {a }}$ ed. São Paulo: Brasiliense.

Ribeiro, D. (1987). O processo civilizatório: etapas da evolução sócio-cultural. $10^{\mathrm{a}}$ ed. Petrópolis: Vozes.

Ribeiro, D. (1970). As Américas e a civilização: processo de formação e causas do desenvolvimento cultural desigual dos povos americanos. Rio de Janeiro: Editora Civilização Brasileira. 
Santos, M. (2000). Por uma outra globalização - do pensamento único à consciência universal. São Paulo: Editora Record.

Santos, B. de S. e Meneses, M. P. (Orgs.) (2010). Epistemologias do Sul. São Paulo: Cortez.

Scolari, C. (2008). Hipermediaciones: elementos para una teoría de la comunicación digital interactiva. Barcelona: Gedisa.

Shirky, C. (2011). A cultura da participação: criatividade e generosidade no mundo conectado. Rio de Janeiro: Zahar.

Silverstone, R. (2002). Por que estudar a mídia? São Paulo: Loyola.

Sodré, M. (2014). A ciência do comum: notas para o método comunicacional. Petrópolis: Vozes.

Sousa, M. W. de. (Org.) (1995). Sujeito, o lado oculto do receptor. São Paulo: Brasiliense.

Thompson, E. P. (1987). A formação da classe operária inglesa. A árvore da liberdade. $3^{a}$ ed. São Paulo: Paz e Terra.

Toaldo, M. e Jacks, N. (2013). Consumo midiático: uma especificidade do consumo cultural, na antessala para os estudos de recepção. Em Associação de Programas de Pós-graduação em Comunicação (Org.), Anais do XXII Encontro da Compós (pp. 1-17). Salvador: Universidade Federal da Bahia.

Trindade, E. e Perez, C. (2014). Dimensões do consumo midiatizado. Em Confederação Ibero-Americana das Associações Científicas e Acadêmicas de Comunicação (Org.), Anais do II Confibercom (pp. 1-10). Braga: Universidade do Minho.

Williams, R. (2011). Cultura e materialismo. São Paulo: Universidade Estadual Paulista. 